\title{
Indicadores físicos e químicos de qualidade de solos de área de mineração e metalurgia de chumbo ${ }^{1}$
}

\section{Physical and chemical soil quality indicators in lead mining and metallurgy area}

\author{
Yara Jurema Barros²; Vander de Freitas Melo²*; Larissa Kummer ${ }^{3}$ Luiz Cláudio de \\ Paula Souza²; Júlio César Azevedo ${ }^{4}$
}

\begin{abstract}
Resumo
As atividades mineração e metalurgia de $\mathrm{Pb}$ em Adrianópolis (PR) causaram impactos ao meio ambiente. Foram determinados os teores de $\mathrm{Pb}, \mathrm{Cu}, \mathrm{Ni}$ e $\mathrm{Zn}$ totais (HF) e extraídos com $\mathrm{HNO}_{3} 0,5$ mol L-1 e algumas características físicas e químicas (fertilidade, capacidade de campo e textura), com o objetivo de avaliar a qualidade dos solos da área, usando a análise por componentes principais (ACP). Foram coletadas quatro amostras compostas de solo em cinco locais, nas profundidades de 0 a 5 e de 5 a 10 cm: solo 1 - referência (mata nativa); solo 2 - resíduos da metalurgia incorporados ao perfil; solos 3 e 6 - próximos a chaminés da fábrica, com potencial de aporte de material particulado; solo 5 - grande volume de resíduos da metalurgia sobre o solo. Os teores máximos de $\mathrm{Pb}$ - total e $\mathrm{Pb}-\mathrm{HNO}_{3}$ foram de 25.930 e $15.370 \mathrm{mg} \mathrm{kg}^{-1}$, respectivamente. Foram identificados dois ambientes com maiores riscos de contaminação: águas superficiais por erosão - solo 5 , com maiores teores totais de $\mathrm{Pb}$, associados a cota elevada e declividade acentuada do terreno; águas subterrâneas por lixiviação, principalmente, se houver acidificação do solo - solo 3, com maiores teores de $\mathrm{Pb}$ extraídos com $\mathrm{HNO}_{3}$ e maior proximidade ao rio Ribeira. As amostras dos solos 5 e 6 foram agrupadas na ACP em função da menor fertilidade e do baixo teor de argila. Já as amostras do solo 3 se diferenciaram das demais por seus maiores teores de nutrientes. Melhores condições físicas e químicas dos solos favorecem o crescimento de plantas, reduzindo a erosão e facilitando trabalhos de fitorremediação da área.

Palavras-chave: Mineração no vale do rio Ribeira, análise por componentes principais, metais pesados
\end{abstract}

\begin{abstract}
The $\mathrm{Pb}$ mining and metallurgy activities in Adrianópolis (PR) caused impacts to the environment. $\mathrm{Pb}$, $\mathrm{Cu}, \mathrm{Ni}$ and $\mathrm{Zn}$ total contents (HF) and extracted with $0.5 \mathrm{~mol} \mathrm{~L}^{-1} \mathrm{HNO}_{3}$ and some physical and chemical characteristics (fertility, field capacity and texture) were determined to assess the area soil quality, through the Principal Component Analysis (PCA). The maximum $\mathrm{Pb}-\mathrm{HF}$ and $\mathrm{Pb}-\mathrm{HNO}_{3}$ contents were, respectively, 25,930 and $15,370 \mathrm{mg} \mathrm{kg}^{-1}$. It were identified two environmental with high contamination risks: surface water by erosive process - soil 5, with higher total $\mathrm{Pb}$ content, associated to the site height and the area pronounced declivity; underground water by leaching - soil 3, with higher $\mathrm{HNO}_{3} \mathrm{~Pb}$ contents, associated
\end{abstract}

1 Parte do trabalho de mestrado do primeiro autor, apresentado ao Programa de Pós-Graduação em Ciência do Solo, Universidade Federal do Paraná.

2 Dept $^{\circ}$ de Solos e Engenharia Agrícola, Universidade Federal do Paraná, UFPR, Rua dos Funcionários 1540, Juvevê, CEP: 80035050, Curitiba, PR. E-mail: yarajuba@gmail.com; vanderfm@ufpr.br; lcsouza@ufpr.br

3 Dept $^{\circ}$ de Engenharia Ambiental, Universidade Tecnológica Federal do Paraná, UTFPR. Linha Santa Bárbara s/n - Caixa Postal 135 - CEP: 85601-970, Francisco Beltrão, PR. E-mail: larikummer@hotmail.com.

$4 \mathrm{Dept}^{\mathrm{O}}$ de Química e Biologia, Universidade Tecnológica Federal do Paraná, UTFPR. Av. Sete de Setembro 3165, CEP: 80203901, Curitiba, PR. E-mail: jcrazevedo@utfpr.edu.br

* Autor para correspondência

Recebido para publicação 10/05/2010 Aprovado em 08/02/2011 
with the proximity of the site to Ribeira River's. The soil 5 samples were grouped (PCA) due to the low fertility and clay content. In the other side, the soil 3 samples were grouped in response of your higher nutrients contents. Higher physical and chemical soil conditions allowed better plant growth, reducing the erosion and improving phytoextraction practices in the area.

Key words: Mining in river Ribeira valley, principal component analysis, heavy metals

\section{Introdução}

A intensificação das atividades industriais, agrícolas e de urbanização tem aumentado o risco de poluição dos solos por metais pesados. Entre as atividades industriais, destaca-se a metalúrgica de metais pesados, que produz grandes quantidades de rejeitos ricos nesses poluentes (AMARAL SOBRINHO et al., 1998; BOSSO; ENZWEILER; ANGÉLICA, 2008). No município de Adrianópolis (PR), por mais de 50 anos, foram desenvolvidas as atividades de mineração e metalurgia de primeira fusão de $\mathrm{Pb}$. $\mathrm{O}$ minério de interesse econômico na área foi a galena (PbS) (MORAES, 1997; SILVA, 1997) e a jazida no município de Adrianópolis (Panelas de Brejaúvas) foram responsáveis por cerca de $55 \%$ da produção de $\mathrm{Pb}$ do Vale do Ribeira; foram extraídos aproximadamente 1.330.000 t de minério, com teor médio de $69 \mathrm{~g} \mathrm{~kg}^{-1}$ de $\mathrm{Pb}$ (MORAES, 1997). Em 1995 a mineradora encerrou suas atividades deixando a céu aberto, sem nenhuma proteção, cerca de 177.000 t de resíduos de beneficiamento de $\mathrm{Pb}$ (EYSINK, 1988; CASSIANO, 2001).

Estudos mais recentes demonstraram que os efeitos da mineração e metalurgia de $\mathrm{Pb}$ ainda se faziam presentes. Destaca-se o trabalho de Cunha (2003), que avaliou o sangue de 335 crianças em idade escolar (7 a 14 anos), entre 1999 e 2000, que moravam no entorno da antiga área de mineração (Vila Mota). Aproximadamente, 70\% das crianças apresentaram teores de $\mathrm{Pb}$ três vezes superiores aos limites preconizados pelo U.S. Center for Disease Control (CDC) e Organização Mundial de Saúde (OMS). No mesmo estudo, verificaram-se altos teores de $\mathrm{Pb}$ nos solos do entorno da fábrica, os quais são eventualmente utilizados para agricultura.

Os solos possuem características únicas quando comparados aos outros componentes da biosfera, pois se apresentam não apenas como um dreno para contaminantes, mas também como tampão natural que controla o transporte de elementos químicos e outras substâncias para a atmosfera, hidrosfera e biota (KABATAPENDIAS; PENDIAS, 2001). A concentração natural de metais pesados no solo depende, entre outros fatores, do material de origem e dos processos de formação do mesmo (FADIGAS et al., 2002; CAMPOS et al., 2003). Fontes antropogênicas contribuem com cerca de $96 \%$ das emissões atmosféricas de $\mathrm{Pb}$, além de serem responsáveis por adições de até 1,16 milhões de t do metal por ano a ecossistemas terrestres e aquáticos (GUILHERME et al., 2002).

Existem duas vias principais para os metais pesados em solos contaminados atingirem os corpos de água e promover a difusão da poluição no ambiente: arraste direto de rejeitos e de partículas de solo por processos erosivos, atingindo os rios e lagos e por percolação desses poluentes no perfil do solo (lixiviação), contaminando as águas subterrâneas. O primeiro processo é extremamente favorecido na área em estudo dado o relevo acidentado e a baixa profundidade efetiva dos solos (ANDRADE et al., 2009a,b). Em solos mais férteis, o melhor crescimento das plantas reduz o potencial erosivo das áreas contaminadas com metais pesados. Alta fertilidade do solo também favorece o crescimento de microrganismos e indivíduos da meso e macrofauna, que além de serem bons indicadores de qualidade ambiental (RAINBOW, 2002; LIAO; CHEN; HUANG, 2005), melhoram 
as características químicas (p. ex., decomposição da matéria orgânica) e físicas (p. ex., agregação) dos solos (SEASTED, 1984; SANGINGA et al., 1992; MUNN; EVANS; CHALK, 2000). Com relação a lixiviação de metais pesados, os fatores mais importantes são: teor desses poluentes nos solos, $\mathrm{pH}$, teor e qualidade da fração argila, teor e qualidade da matéria orgânica, profundidade efetiva do solo, concentração e natureza dos cátions e ânions acompanhantes, etc. (ELLIS; KNEZEK, 1977; FARRAH; PICKERING, 1978; LOGAN; CHANEY, 1983; ELLIOTT; LIBERATI; HUANG, 1986; HARTER; NAIDU, 1995; SPARKS, 2003).

Nesse estudo foram determinados os teores de $\mathrm{Cu}, \mathrm{Ni}, \mathrm{Pb}$ e $\mathrm{Zn}$ e algumas características físicas e químicas (relacionadas à fertilidade dos solos), com o objetivo de avaliar a qualidade de solos de área de mineração e metalurgia de $\mathrm{Pb}$, no município de Adrianópolis (PR), usando a análise por componentes principais.

\section{Material e Métodos}

\section{Área de estudo e amostragem dos solos}

A área de mineração e metalurgia de $\mathrm{Pb}$ situa-se no município de Adrianópolis (PR), na localidade de Panelas de Brejaúvas, distante 12 $\mathrm{km}$ da sede do município e próxima às margens do rio Ribeira, fronteira com o Estado de São Paulo. Na área era evidente a grande degradação do meio ambiente, com ocorrência de intenso processo erosivo, facilitado pelo relevo acidentado (Figura 1), grande número de bocas de túneis de mineração, estradas degradadas, extensas áreas com escórias do beneficiamento de $\mathrm{Pb}$ espalhados sobre o solo e abandono da fábrica.

A quadrícula de Adrianópolis apresenta geologia complexa, com as seguintes formações e litologias em ordem decrescente de ocorrência (OLIVEIRA et al., 2002): 1) complexos granitóides (Três Córregos e Cunhaporanga); 2) dolomitos e carbonatos com baixo grau metamórfico; 3) rochas vulcano-sedimentar, com domínio de rochas psamo-pelíticas; 4) carbonatos e rochas psamo-pelíticas; 5) gnaisses variados, xistos e quartzitos de baixo a médio grau metamórfico e; 6) metabrechas, metaconglomerados e metapelitos.

A compartimentalização da paisagem em unidades mais homogêneas, com menor variabilidade das classes de solos, usando o geoprocessamento, e a identificação de diferentes ambientes em função da forma de contaminação possibilitaram uma amostragem mais representativa da área sob influência direta das atividades de mineração e metalurgia de $\mathrm{Pb}$ (Figura 1). Os critérios para seleção dos locais de amostragem dos solos foram apresentados por Andrade et al. (2009a) e suas características estão na Tabela 1 .

Retiraram-se amostras compostas de solo em quatro quadrantes (A, B, C, D - área do quadrante $1,5 \times 1,5 \mathrm{~m}$ ) no entorno dos pontos selecionados (Figura 1), com o propósito de verificar variações nos atributos químicos e físicos a curtas distâncias horizontais. Para a obtenção da amostra composta foram homogeneizadas 10 amostras simples, retiradas de 0 a 5 e de 5 a $10 \mathrm{~cm}$ (horizonte A) no interior do quadrante. A amostragem na camada mais superficial dos solos objetivou representar a região de maior contaminação e acúmulo de metais pesados (GOMES et al. 1997; AMARAL SOBRINHO, 1998; ANDRÉ et al.2003). Com esses procedimentos, coletaram-se 40 amostras compostas de solos, as quais foram secas ao ar, moídas e passadas em peneira de plástico de malha de $2 \mathrm{~mm}$ (TFSA). 


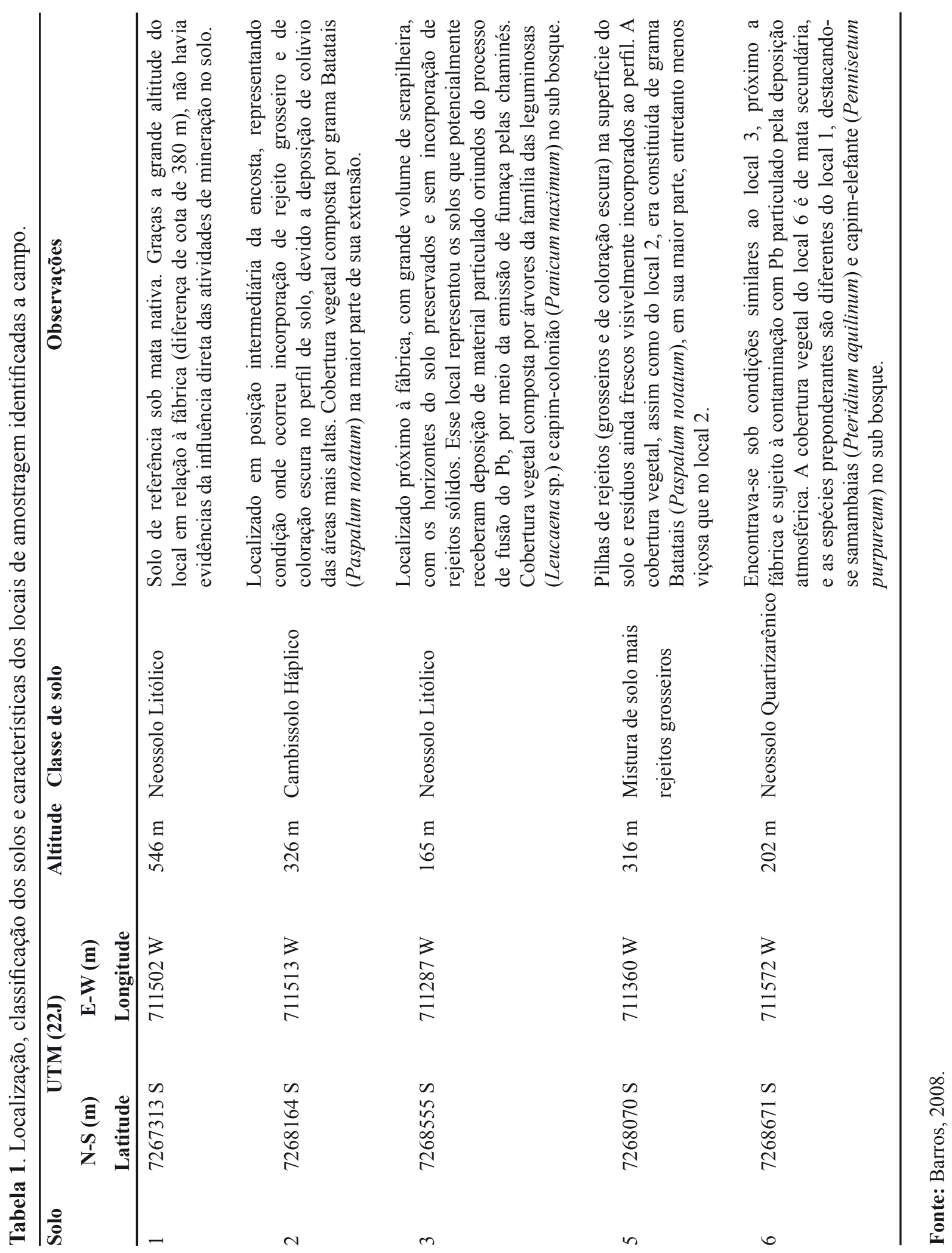


Figura 1. Foto aérea georeferenciada com os compartimentos geomorfológicos (linhas pretas mais finas), localização da fábrica abandonada e locais de coleta $(1,2,3,5$ e 6) dentro da área selecionada para 0 estudo (contorno em linha preta mais espessa). Os pontos menores representam a coleta prévia de solos para reconhecimento da área e definição dos ambientes em função das diferentes formas de contaminação, conforme detalhes apresentados por Andrade et al. (2009a).

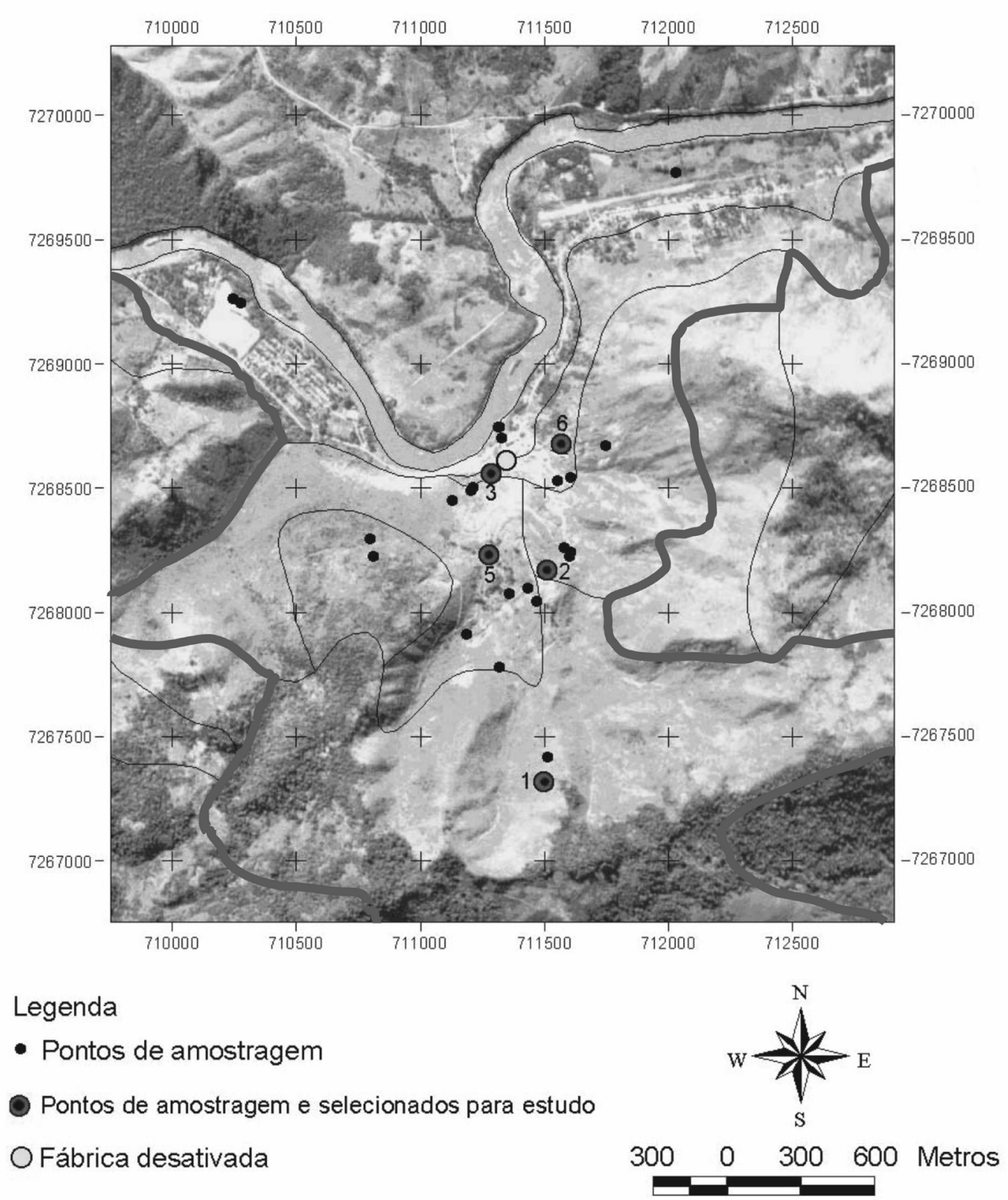

Base cartográfica: Carta de Apiaí, IBGE, Secretaria de Planejamento da Presidência da República. Sistema de Proteção Universal Transversa de Mercator.

Datum: SAD-69. 


\section{Fertilidade}

Para a caracterização química de rotina (fertilidade) das amostras de TFSA utilizaram os métodos descritos em EMBRAPA (1997): pH em $\mathrm{H}_{2} 0$; acidez potencial não-trocável $(\mathrm{H})$; $\mathrm{Ca}^{2+}$, $\mathrm{Mg}^{2+}, \mathrm{Al}^{3+}, \mathrm{K}^{+}$e $\mathrm{Na}^{+}$trocáveis. $\mathrm{O} \mathrm{C}$ orgânico foi determinado pelo método fotocolorimétrico, com solução oxidante de $\mathrm{Na}_{2} \mathrm{Cr}_{2} \mathrm{O}_{7}$ e $\mathrm{H}_{2} \mathrm{SO}_{4}$ concentrado a frio (UFPR, 2003). Por se tratar de uma região calcária, a extração do $\mathrm{P}$ disponível foi com $\mathrm{NaHCO} 30,5 \mathrm{~mol} \mathrm{~L}^{-1}, \mathrm{pH}$ ajustado em 8,5 , na proporção de 1:20, por meio de agitação, filtragem e adição de carbono ativado para a obtenção de extrato sem turbidez (OLSEN; SOMMERS;1982). Para determinação do $\mathrm{N}$ total utilizou-se o método adaptado de Kjedahl, em que $1 \mathrm{~g}$ de TFSA, previamente seco a $60^{\circ} \mathrm{C}$, foi digerido em tubos com capacidade para $80 \mathrm{~mL}$ com pastilha de $1 \mathrm{~g}$ de $\mathrm{CuSO}_{4}$ e $\mathrm{K}_{2} \mathrm{SO}_{4}$ combinados, como catalizador, e 7,5 mL de $\mathrm{H}_{2} \mathrm{SO}_{4}$ concentrado (JACKSON, 1970).

\section{Metais pesados}

\section{Extração com $\mathrm{HNO}_{3} 0,5 \mathrm{~mol} \mathrm{~L} \mathrm{~L}^{-1}$}

Cerca de $10 \mathrm{~g}$ de solo, previamente seco a 50 ${ }^{\circ} \mathrm{C}$, durante $24 \mathrm{~h}$, foi colocado para reagir com $25 \mathrm{~mL}$ de $\mathrm{HNO}_{3} 0,5 \mathrm{~mol} \mathrm{~L}^{-1}$ em frasco de vidro. Os frascos foram colocados em uma bandeja de alumínio contendo óleo vegetal, sobre uma chapa elétrica (temperatura do óleo ajustada em $113{ }^{\circ} \mathrm{C}$ ), onde permaneceram por $25 \mathrm{~min}$ (KNUDSEN; PETERSON; PRATT, 1986). Os teores de $\mathrm{Pb}, \mathrm{Cu}$, Ni e $\mathrm{Zn}$ foram determinados por espectroscopia de emissão atômica com plasma indutivamente acoplado (ICP-AES).

Em estudo de fitoextração (girassol, aveiapreta e grama batatais) e de disponibilidade de $\mathrm{Pb}$ e $\mathrm{Zn}$ [extrações com DTPA-TEA pH 7,3, $\mathrm{Ca}\left(\mathrm{NO}_{3}\right)_{2}, 0,5 \mathrm{~mol} \mathrm{~L}^{-1}, \mathrm{HNO}_{3}$ 0,5, 1,0 e $4 \mathrm{~mol} \mathrm{~L}^{-1}$ e $\mathrm{HNO}_{3} / \mathrm{HCl}$ concentrados (3:1)] de amostras de solos retiradas dos mesmos locais do presente estudo, Andrade et al. (2009a,b) observaram que a extração com $\mathrm{HNO}_{3} 0,5$ mol L $\mathrm{L}^{-1}$ fervente foi o método que melhor se correlacionou com a absorção desses metais pelas plantas (coeficientes de correlação entre 0,97*, p $<0,05$ e $1,00 * * *, p<0,0001)$. Contudo, devido ao alto poder de extração de metais pesados da solução de $\mathrm{HNO}_{3}$ 0,5 mol L-1 (SOON; BATES, 1982), mesmo com os altos valores dos coeficientes de correlação, os teores de $\mathrm{Pb}$ na parte aérea das plantas representaram apenas cerca $2 \%$ daqueles obtidos nos solos.

\section{Teores totais}

A digestão das amostras foi realizada em forno de microondas, colocando-se $0,25 \mathrm{~g}$ de solo, previamente seco a $50{ }^{\circ} \mathrm{C}$ por $24 \mathrm{~h}$, na presença de $4 \mathrm{~mL}$ de $\mathrm{HNO}_{3}, 3 \mathrm{~mL}$ de $\mathrm{HF}$ concentrados e $1 \mathrm{~mL}$ de $\mathrm{H}_{2} \mathrm{O}_{2} 30 \%$ (v/v) (LIM; JACKSON, 1986, com modificações). Os frascos do forno microondas foram submetidos a $10 \mathrm{~min}$ de aquecimento a uma potência de $1.000 \mathrm{~W}$ até atingir a temperatura de $200 \pm 2{ }^{\circ} \mathrm{C}$, a qual foi mantida por $20 \mathrm{~min}$. Após $30 \mathrm{~min}$ de resfriamento das amostras no interior do aparelho, a suspensão foi filtrada, aferindo-se a massa do extrato para aproximadamente $15 \mathrm{~g}$ com água deionizada. $\mathrm{O}$ volume foi determinado com base na massa e densidade do líquido. Os teores de metais pesados foram determinados por ICP-AES.

\section{Análises físicas}

A análise textural da TFSA foi determinada pelo método da pipeta, segundo procedimento apresentado por EMBRAPA (1997), após remoção prévia da matéria orgânica com $\mathrm{H}_{2} \mathrm{O}_{2} 30$ $\%$ (v/v). A capacidade de campo foi determinada pelo método da mesa de tensão, com coluna de $60 \mathrm{~cm}$ (pressão de $6 \mathrm{kPa}$ ) (EMBRAPA, 1997).

\section{Análise estatística}


O conjunto de métodos analíticos físicos e químicos, cujos resultados configuram-se em uma matriz multidimensional, foi submetido à análise multivariada por técnicas de análise por componentes principais (ACP), que consiste de um conjunto de ferramentas estatísticas orientadas a comprimir a matriz original, sem perda de informação relevante (GELADI et al., 1989). A primeira análise de ACP foi com teores de metais pesados visando discriminar os solos com maiores problemas de contaminação decorrentes das atividades de mineração e metalurgia de $\mathrm{Pb}$. Os resultados das análises químicas e físicas foram usados para agrupar solos quanto à fertilidade natural, característica importante, por exemplo, para revegetação das áreas degradadas, proteção contra os processos erosivos e em práticas de recuperação, como a fitorremediação (ANDRADE et al., 2009a).

\section{Resultados e Discussão}

\section{Metais pesados}

Com exceção do solo de referência (solo 1) verificou-se que as atividades de mineração e metalurgia de $\mathrm{Pb}$ promoveram expressivo incremento nos teores de metais pesados, principalmente, $\mathrm{Pb}$ e $\mathrm{Zn}$ (Tabela 2). Houve inversão nos teores de $\mathrm{Pb}$ - total e $\mathrm{Pb}-\mathrm{HNO}_{3} 0,5$ mol L ${ }^{-1}$ nos solos 2 e 5, contaminados diretamente com resíduos sólidos (Tabela 1). A ocorrência desses resíduos sobre a superfície e no perfil do solo 5 determinou altos teores de $\mathrm{Pb}$ - total nas camadas de 0 a 5 e de 5 a $10 \mathrm{~cm}$ (máximo $25.930 \mathrm{mg} \mathrm{kg}^{-1}$ ), porém, os teores com $\mathrm{HNO}_{3}$ foram bem inferiores (máximo $2.868 \mathrm{mg} \mathrm{kg}^{-1}$ ). Já a incorporação dos resíduos no perfil do solo 2, por meio de processos erosivos, contribuiu para sua solubilização e aumento nos teores com $\mathrm{HNO}_{3}$ em detrimento aos totais. Os maiores teores de $\mathrm{Zn}$ - total em relação ao $\mathrm{Pb}$ no solo 5 , indica que o processo de mineração e metalurgia também concentrou formas não disponíveis de $\mathrm{Zn}$ nos resíduos.

Os solos 3 e 6, sujeitos ao mesmo processo de contaminação (via deposição de material particulado), dada a proximidade com a fábrica, apresentaram teores muitos distintos de metais pesados (Tabela 2). O solo 6, por ser mais arenoso (teor de argila variando de 72,7 a 171,0 $\mathrm{g} \mathrm{kg}^{-1}$ - Tabela 3) possui menor capacidade de adsorção e acúmulo de metais pesados que o solo 3. Provavelmente, devido a baixa capacidade tampão do solo 6, durante décadas de atividades na fábrica, grande quantidade de metais pesados foram lixiviados e atingiram o rio Ribeira. No solo 3 os teores de $\mathrm{Pb}-\mathrm{HNO}_{3}$ atingiram 14.458 $\mathrm{mg} \mathrm{kg}{ }^{-1}$, sendo muito próximos ao teor total da mesma amostra (coleta em setembro/2007, de 0 a $5 \mathrm{~cm} \mathrm{-} 15.248 \mathrm{mg} \mathrm{kg}^{-1}$ ). As atividades de mineração e de processamento de minérios sulfetados de $\mathrm{Pb}$ produzem, além de rejeitos e escória de forno, emissões gasosas contendo $\mathrm{SO}_{2}$ e $\mathrm{CO}$ e poeiras contendo partículas com 20 a 65 $\%$ de Pb (BURGESS, 1995).

Dessa forma, os rejeitos espalhados por toda área da Mina de Panelas de Brejaúvas tiveram um papel agressivo ao meio ambiente, porém, as emissões de materiais particulados pela preparação e beneficiamento do minério de $\mathrm{Pb}$ foram mais deletérias. Devido aos elevados teores de $\mathrm{Pb}$ - total e $\mathrm{Pb}-\mathrm{HNO}_{3}$, a grande declividade do terreno (Figuras 1) e reduzida profundidade efetiva (Neossolos e Cambissolo - Tabela 1), nos solos sob influência direta das atividades de mineração e metalurgia recomenda-se a realização imediata de práticas de remediação da área. 
Tabela 2. Teores de $\mathrm{Pb}, \mathrm{Cu}$, $\mathrm{Ni}$ e $\mathrm{Zn}$ totais (HF) e extraídos com $\mathrm{HNO}_{3}$ nas camadas de 0 a $5 \mathrm{~cm}$ e de 5 a $10 \mathrm{~cm} \mathrm{dos} \mathrm{solos}^{(1)}$

\section{$\mathrm{HF}, \mathrm{HNO}_{3}$ concentrados $+\mathrm{H}_{2} \mathrm{O}_{2} \quad \mathrm{HNO}_{3} 0,5 \mathrm{~mol} \mathrm{~L}^{-1}$}

$\begin{array}{lllllllllll}\text { Solo } & \text { Quadrante } & \mathrm{Pb} & \mathrm{Cu} & \mathrm{Ni} & \mathrm{Zn} & \mathrm{Pb} & \mathrm{Cu} & \mathrm{Ni} & \mathrm{Zn}\end{array}$

\begin{tabular}{|c|c|c|c|c|c|c|c|c|}
\hline \multirow[b]{2}{*}{1} & \multirow[b]{2}{*}{$\mathrm{A}$} & \multicolumn{7}{|c|}{0 a $5 \mathrm{~cm}$} \\
\hline & & 464,5 nd & 15,3 & 293,7 & 420,6 & nd & 7,4 & 81,9 \\
\hline 1 & $\mathrm{~B}$ & 577,9 nd & 11,9 & 394,1 & 520,9 & nd & 6,3 & 93,2 \\
\hline 1 & $\mathrm{C}$ & $813,2 \quad 97,6$ & 26,5 & 211,8 & 677,9 & 20,7 & 8,8 & 108,5 \\
\hline 1 & $\mathrm{D}$ & $764,6 \quad 149,2$ & 49,8 & 105,2 & 362,7 & 7,9 & 7,9 & 70,2 \\
\hline 2 & A & $5761,1 \quad 235,9$ & 21,1 & 317,2 & 4361,1 & 136,5 & 5,5 & 242,2 \\
\hline 2 & $\mathrm{~B}$ & $5322,2 \quad 247,2$ & 19,9 & 424,1 & 4779,3 & 106,8 & 6,9 & 282,3 \\
\hline 2 & $\mathrm{C}$ & $6269,7 \quad 393,2$ & 31,4 & 388,9 & 4153,5 & 85,9 & 3,9 & 228,9 \\
\hline 2 & $\mathrm{D}$ & $10205,8737,4$ & 52,8 & 796,8 & 2714,6 & 51,1 & 1,6 & 263,9 \\
\hline 3 & A & $14179,71708,8$ & 43,8 & 1196,3 & 9467,2 & 1014,3 & 28,7 & 985,2 \\
\hline 3 & $\mathrm{~B}$ & $15248,31918,9$ & 46,4 & 1160,8 & 14457,9 & 1580,5 & 34,2 & 1071,4 \\
\hline 3 & $\mathrm{C}$ & $14863,01756,2$ & 59,9 & 1222,4 & 12796,1 & 1204,7 & 27,8 & 962,5 \\
\hline 3 & $\mathrm{D}$ & $17460,93595,4$ & 89,5 & 1668,2 & 12007,5 & 1443,1 & 25,1 & 808,9 \\
\hline 5 & $\mathrm{~A}$ & $17261,5682,8$ & 7,5 & 23434,6 & 2410,5 & 32,6 & nd & 2573,7 \\
\hline 5 & B & $19237,5598,0$ & 12,8 & 23337,3 & 2499,0 & 26,1 & nd & 2528,5 \\
\hline 5 & $\mathrm{C}$ & $22109,3937,6$ & 28,6 & 33371,9 & 2849,5 & 44,8 & nd & 2535,9 \\
\hline 5 & $\mathrm{D}$ & $25190,81223,7$ & 31,1 & 54238,4 & 1910,9 & 18,7 & nd & 2527,0 \\
\hline 6 & $\mathrm{~A}$ & 734,6 nd & nd & nd & 472,5 & nd & nd & nd \\
\hline 6 & B & 1301,9 nd & nd & nd & 859,1 & nd & nd & nd \\
\hline 6 & $\mathrm{C}$ & $788,3 \quad 78,4$ & 5,3 & 40,5 & 698,7 & 30,4 & nd & 18,8 \\
\hline 6 & $\mathrm{D}$ & $560,1 \quad 322,7$ & 11,2 & nd & 493,6 & 28,7 & nd & nd \\
\hline
\end{tabular}

\begin{tabular}{llllllllll}
\hline & \multicolumn{10}{c}{$\mathbf{5} \mathbf{a ~ 1 0} \mathbf{~ c m}$} \\
1 & A & 475,4 & nd & 15,9 & 99,9 & 290,7 & nd & 8,6 & 68,0 \\
1 & B & 499,5 & nd & 12,98 & 189,8 & 445,2 & nd & 7,5 & 73,2 \\
1 & C & 1283,9 & 107,4 & 29,9 & 3065,3 & 723,9 & 16,4 & 9,2 & 94,2 \\
1 & D & 1025,8 & 264,7 & 65,2 & 93,0 & 647,0 & 13,0 & 11,5 & 18,7 \\
2 & A & 4173,4 & 109,3 & 22,4 & 190,2 & 3101,7 & 44,8 & 7,1 & 117,1 \\
2 & B & 4269,8 & 159,6 & 21,0 & 268,9 & 4083,9 & 107,9 & 7,9 & 194,7 \\
2 & C & 5497,5 & 336,9 & 37,9 & 334,5 & 4262,8 & 69,8 & 5,0 & 162,4 \\
2 & D & 5885,9 & 536,0 & 57,9 & 495,4 & 3883,2 & 59,6 & 4,4 & 150,0 \\
3 & A & 17203,1 & 2068,6 & 47,4 & 1078,9 & $15370,51876,2$ & 32,7 & 975,1 \\
3 & B & 15406,5 & 1882,5 & 48,1 & 1058,9 & $15230,21839,1$ & 35,3 & 999,2
\end{tabular}




\begin{tabular}{|c|c|c|c|c|c|c|c|c|c|}
\hline \multicolumn{10}{|c|}{ Continuação Tabela 2} \\
\hline 3 & $\mathrm{C}$ & 8996,7 & 785,1 & 43,9 & 925,4 & 8176,9 & 595,1 & 22,3 & 827,1 \\
\hline 3 & $\mathrm{D}$ & 14096,3 & 4032,9 & 104,9 & 975,7 & 8438,1 & 1794,5 & 26,0 & 745,7 \\
\hline 5 & A & 10345,6 & 5393,2 & 8,7 & 21539,1 & 1346,5 & 22,5 & nd & 1995,6 \\
\hline 5 & B & 18165,8 & 607,7 & 14,6 & 23482,9 & 2868,5 & 43,1 & nd & 2442,7 \\
\hline 5 & $\mathrm{C}$ & 17887,9 & 831,6 & 23,7 & 34521,8 & 2043,4 & 32,0 & nd & 2361,9 \\
\hline 5 & $\mathrm{D}$ & 25930,3 & 1335,9 & 38,3 & 51601,2 & 1969,9 & 13,1 & nd & 2391,8 \\
\hline 6 & A & 903,9 & nd & nd & nd & 534,9 & nd & nd & nd \\
\hline 6 & B & 871,1 & nd & nd & nd & 552,8 & nd & nd & nd \\
\hline 6 & $\mathrm{C}$ & 1251,2 & 88,8 & 6,8 & 79,1 & 823,6 & 32,2 & nd & 25,3 \\
\hline \multirow[t]{2}{*}{6} & $\mathrm{D}$ & 556,5 & 89,4 & 9,8 & nd & 540,6 & 40,4 & nd & nd \\
\hline & Mé & & & & & & & & \\
\hline 1 & & 738,1 & 77,4 & 28,7 & 556,6 & 511,1 & 7,3 & 8,4 & 76,0 \\
\hline 2 & & 5923,2 & 344,4 & 33,1 & 402,0 & 3917,5 & 82,8 & 5,3 & 205,2 \\
\hline 3 & & 14681,8 & 2218,6 & 60,5 & 1160,8 & 11993,1 & 1418,4 & 29,0 & 921,9 \\
\hline 5 & & 19516,1 & 826,3 & 20,7 & 33190,9 & 2237,3 & 29,1 & nd & 2419,6 \\
\hline 6 & & 871,0 & 72,4 & 4,1 & 15,0 & 622,0 & 16,5 & nd & 5,5 \\
\hline
\end{tabular}

(1) nd - teores abaixo do nível de detecção do método analítico empregado (ICP-AES). As letras A, B, C e D representam as amostras compostas retiradas de quatro quadrantes (área útil de cada quadrante 1,5 x 1,5 m), dispostos lado a lado, em cada solo.

Os teores totais de $\mathrm{Pb}$ tiveram grandes variações entre os quadrantes (A, B, C, D), delimitados lado a lado em cada ponto de coleta. Barbar e Melo (2008) estudaram as variações nos teores totais de metais nos horizonte A e B de cinco solos da região metropolitana de Curitiba (amostragem composta em quatro quadrantes de $1 \mathrm{x} 1 \mathrm{~m}$ ) e encontraram valores de coeficientes de variação máximos para $\mathrm{Zn}, \mathrm{Mn}, \mathrm{Cu}, \mathrm{Ni}, \mathrm{Pb}$ e Cr de $85,28,64,17,75$ e $13 \%$, respectivamente. Isso confirma que, mesmo sendo características mais estáveis, os teores totais de elementos sofrem grandes variações a curtas distâncias horizontais no solo (repetições coletadas no mesmo horizonte e em solos próximos), principalmente, na área do presente estudo pela intensa interferência antrópica.

No gráfico de ordenamento das variáveis ("scores") da análise por componentes principais
(ACP) da camada 0 a $5 \mathrm{~cm}$ (Figura 2a) verificouse clara separação das amostras do solo 5, tomadas em diferentes quadrantes. A formação desse grupo homogêneo de amostras foi determinada, principalmente, por seus maiores teores de $\mathrm{Pb}$ e $\mathrm{Zn} \mathrm{-} \mathrm{totais;} \mathrm{observar} \mathrm{que} \mathrm{essas} \mathrm{variáveis} \mathrm{estão}$ posicionadas na parte superior do gráfico (Figura 2b), similar às amostras do solo 5 .

Os altos teores totais desses metais na camada de 0 a $5 \mathrm{~cm}$ (Tabela 2) confirmam esse comportamento. Nessas condições, o maior risco de poluição dos rios seria pelo arraste direto das partículas de rejeito e de solo contaminado por erosão, processo facilitado pelas condições pedológicas e de relevo da área. A remoção e encapsulamento desses rejeitos em aterros industriais também reduziriam o risco de passagem desses metais pesados para formas mais disponíveis. 
Tabela 3. Propriedades físicas das camadas de 0 a $5 \mathrm{~cm}$ e de 5 a $10 \mathrm{~cm}$ dos solos ${ }^{(1)}$.

\begin{tabular}{|c|c|c|c|c|c|}
\hline \multirow{3}{*}{ Solo } & \multirow{3}{*}{$\begin{array}{c}\text { Quadrante } \\
\text { amostrado } \\
\end{array}$} & Capacidade de Campo & Areia & Argila & Silte \\
\hline & & \multicolumn{4}{|c|}{$\mathrm{g} \mathrm{kg}^{-1}$} \\
\hline & & \multicolumn{4}{|c|}{0 a $5 \mathrm{~cm}$} \\
\hline 1 & $\mathrm{~A}$ & 556,8 & 207,5 & 371,7 & 420,9 \\
\hline 1 & $\mathrm{~B}$ & 571,4 & 173,0 & 465,4 & 361,6 \\
\hline 1 & $\mathrm{C}$ & 663,0 & 179,8 & 477,2 & 343,0 \\
\hline 1 & $\mathrm{D}$ & 754,0 & 166,3 & 628,7 & 205,0 \\
\hline 2 & $\mathrm{~A}$ & 553,4 & 113,4 & 428,7 & 457,9 \\
\hline 2 & $\mathrm{~B}$ & 617,3 & 97,9 & 399,8 & 502,3 \\
\hline 2 & $\mathrm{C}$ & 615,0 & 97,7 & 435,0 & 467,3 \\
\hline 2 & $\mathrm{D}$ & 789,7 & 111,8 & 552,7 & 335,5 \\
\hline 3 & $\mathrm{~A}$ & 650,0 & 225,6 & 426,1 & 348,2 \\
\hline 3 & $\mathrm{~B}$ & 509,4 & 262,3 & 371,4 & 366,4 \\
\hline 3 & $\mathrm{C}$ & 585,9 & 232,6 & 460,1 & 307,4 \\
\hline 3 & $\mathrm{D}$ & 664,1 & 184,8 & 570,8 & 244,4 \\
\hline 5 & A & 77,0 & 763,4 & 144,1 & 92,5 \\
\hline 5 & B & 103,3 & 931,9 & 53,9 & 14,2 \\
\hline 5 & $\mathrm{C}$ & 89,5 & 949,9 & 45,0 & 05,1 \\
\hline 5 & $\mathrm{D}$ & 83,5 & 954,7 & 41,4 & 03,9 \\
\hline 6 & A & 255,1 & 692,5 & 91,7 & 215,8 \\
\hline 6 & $\mathrm{~B}$ & 199,5 & 709,7 & 171,0 & 119,3 \\
\hline 6 & $\mathrm{C}$ & 176,9 & 747,9 & 130,4 & 121,7 \\
\hline \multirow[t]{2}{*}{6} & $\mathrm{D}$ & 213,7 & 791,1 & 147,7 & 61,2 \\
\hline & & \multicolumn{4}{|c|}{5 a $10 \mathrm{~cm}$} \\
\hline 1 & A & 334,4 & 202,9 & 476,7 & 320,4 \\
\hline 1 & B & 342,4 & 180,9 & 442,8 & 376,3 \\
\hline 1 & $\mathrm{C}$ & 375,2 & 136,2 & 524,6 & 339,3 \\
\hline 1 & $\mathrm{D}$ & 413,8 & 167,7 & 611,3 & 221,0 \\
\hline 2 & A & 323,3 & 81,5 & 456,4 & 462,1 \\
\hline 2 & B & 350,6 & 91,6 & 394,9 & 513,5 \\
\hline 2 & $\mathrm{C}$ & 365,2 & 104,8 & 430,6 & 464,6 \\
\hline 2 & $\mathrm{D}$ & 352,8 & 96,7 & 588,7 & 314,6 \\
\hline 3 & A & 308,8 & 233,9 & 401,3 & 364,9 \\
\hline 3 & B & 312,3 & 207,7 & 447,6 & 344,8 \\
\hline 3 & $\mathrm{C}$ & 246,1 & 230,3 & 521,7 & 248,0 \\
\hline 3 & $\mathrm{D}$ & 354,3 & 198,5 & 600,3 & 201,2 \\
\hline
\end{tabular}




\section{Continuação Tabela 3}

\begin{tabular}{llllll}
5 & A & 94,4 & 600,4 & 202,3 & 197,2 \\
5 & B & 96,3 & 866,5 & 82,9 & 50,7 \\
5 & C & 95,4 & 819,2 & 83,6 & 97,2 \\
5 & D & 70,6 & 924,4 & 68,5 & 07,1 \\
6 & A & 117,8 & 790,3 & 72,7 & 137,0 \\
6 & B & 133,5 & 696,6 & 152,6 & 150,8 \\
6 & C & 131,2 & 766,4 & 113,3 & 120,4 \\
6 & D & 116,5 & 855,8 & 122,6 & 21,6 \\
\hline & Média Geral & & & \\
\hline 1 & & 501,4 & 176,8 & 499,8 & 323,4 \\
2 & & 495,9 & 99,4 & 460,9 & 439,7 \\
3 & & 453,9 & 222,0 & 474,9 & 303,2 \\
5 & & 88,8 & 851,3 & 90,2 & 58,5 \\
6 & & 168,0 & 756,3 & 125,3 & 118,5 \\
\hline
\end{tabular}

${ }^{(1)}$ As letras A, B, C e D representam as amostras compostas retiradas de quatro quadrantes.

As amostras da camada de 0 a $5 \mathrm{~cm}$ do solo 3 (grupo no quadrante inferior esquerdo - Figura 2a) representam maiores risco de contaminação por lixiviação: teores mais altos de $\mathrm{Pb}-\mathrm{HNO}_{3}$ e proximidade dos solos ao rio Ribeira. Além do $\mathrm{Pb}$, as emissões atmosféricas também enriqueceram os solos com formas mais disponíveis de $\mathrm{Cu}$ (Figura 2b). Na camada de 0 a $5 \mathrm{~cm}$ do solo 3 , os teores de $\mathrm{Cu}-\mathrm{HNO}_{3}$ 0,5 mol L-1 variaram de 1.014 a 1.580 $\mathrm{mg} \mathrm{kg}^{-1}$ ( Tabela 2).

As amostras do solo 2 formaram um grupo homogêneo localizado na divisória dos quadrantes superior e inferior (Figura 2a), o que está de acordo com os menores teores de $\mathrm{Pb}$ - total dessas amostras em relação ao solo 5 e de $\mathrm{Pb}-\mathrm{HNO}_{3}$ em relação às amostras do solo 3; $\mathrm{Pb}$ total no quadrante superior e $\mathrm{Pb}-\mathrm{HNO}_{3}$ no quadrante inferior do gráfico (Figura $2 b)$.

Houve tendência das amostras do solo 6, com menores teores totais de metais pesados, serem agrupadas com as amostras do solo de referência (solo 1) (quadrante direito da Figura 2a), indicando menor risco de contaminação ambiental.

As únicas dispersões das amostras tomadas em diferentes quadrantes foram para os solos 2 e 6 (2D - quadrante superior esquerdo e 6D - inferior direito). A amostra 2D apresentou o maior teor de $\mathrm{Pb}$ - total em relação às demais coletas para esse solo, o que justificou a sua dispersão para o quadrante superior (Figura 2a), acompanhando o posicionamento dessa variável (Figura 2b). Por outro lado, a amostra 6D apresentou o menor teor de $\mathrm{Pb}$ - total, se posicionando mais abaixo em relação às demais amostras desse solo.

A ACP para camada de 5 a $10 \mathrm{~cm}$ (Figura 3) mostrou o mesmo comportamento apresentado para a camada mais superficial, com evidente separação das amostras dos solos 3 e 5 . 
Figura 2. Análise de Componente Principal dos dados de metais pesados da camada de 0 a $5 \mathrm{~cm}$ : valores de "scores" para as amostras analisadas e formação de grupos de amostras semelhantes (a) e valores de "loadings" para as variáveis levando-se em consideração as componentes principais 1 e 2 (b).

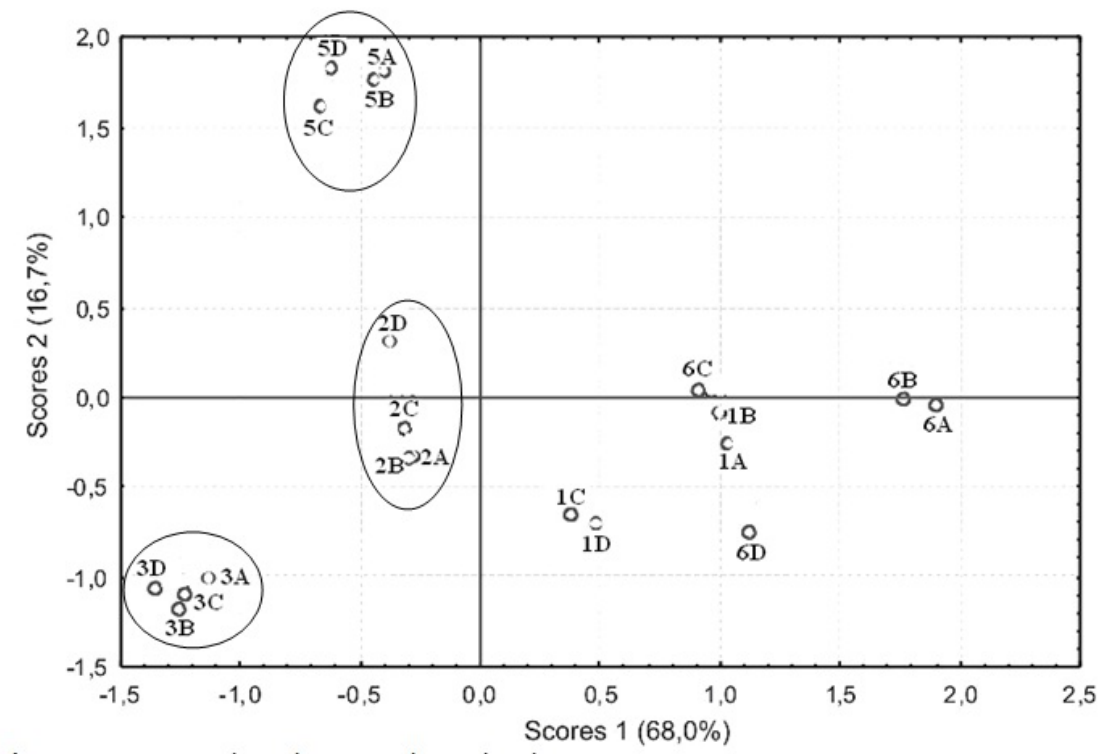

NOTA: o número representa o solo e a letra o quadrante de coleta.

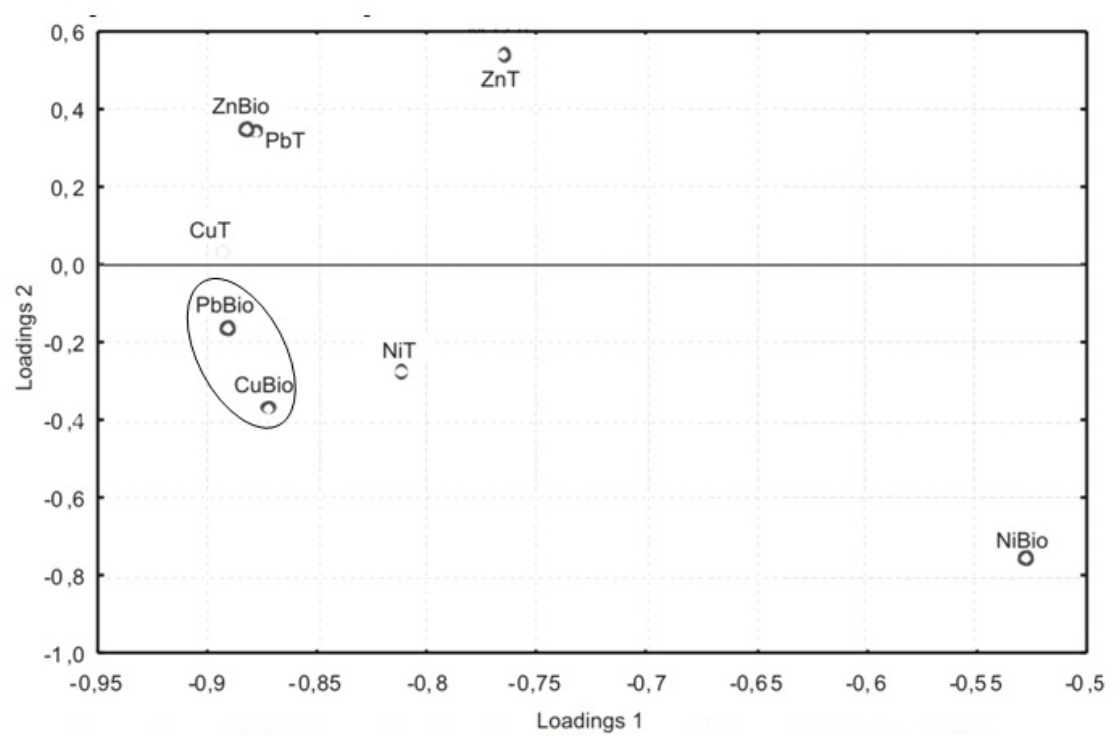

Propriedades físicas e químicas

A textura dos solos (Tabela 3 ) foi fortemente influenciada pelo material de origem. Os altos teores de silte são compatíveis com o reduzido grau de intemperismo dos solos (Neossolos e Cambissolo), determinado pelo relevo forte ondulado/montanhoso da região. Os solos 1 a 3 apresentam textura argilosa, formados por gnaisses e rochas calcárias. Já o solo 6 representou a área de solos arenosos, localizados na encosta, à esquerda da fábrica (Figura 1), originados do intemperismo de quartzitos (OLIVEIRA et al., 2002). Os altos teores de areia do solo 5, localizado na mesma área dos solos 1 a 3, foi devido a grande ocorrência de rejeitos sólidos, de coloração escura, incorporados ao perfil. Esses resíduos passaram pela peneira de $2 \mathrm{~mm}$ de abertura, superestimando os teores de areia. Os 
Figura 3. Análise de Componente Principal dos dados de metais pesados da camada de 5 a $10 \mathrm{~cm}$ : diagrama de ordenação das amostras ("scores") e formação de grupos de amostras semelhantes (a) e diagrama de ordenamento das variáveis ("loadings") levando-se em consideração as componentes principais 1 e 2 (b).
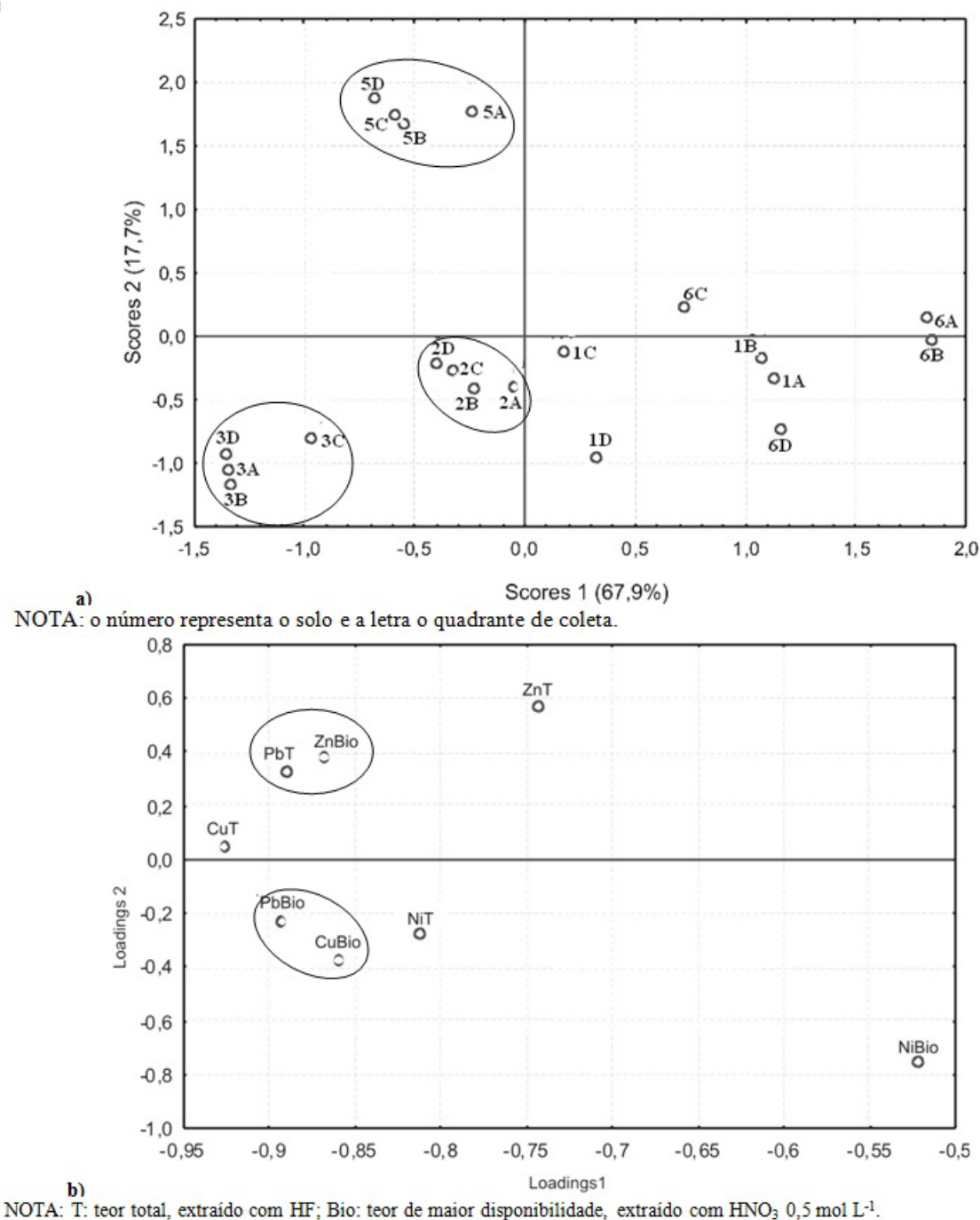

valores da capacidade de campo acompanharam os teores de argila das amostras.

O solo 6, com menor teor de metais pesados (agrupamento com as amostras do solo de referência - Figuras 2 e 3), devido seu baixo teor de argila (Tabela 3) e de CTC total (Tabela 4), apresenta baixa capacidade tampão, o que deve ter contribuído para intensa lixiviação de metais pesados durante o período de atividade da fábrica (50 anos). Nas condições atuais, a baixa capacidade tampão do solo 5 (baixo teor de argila e valor de CTC total) traz mais riscos ambientais, pois as partículas de resíduos incorporadas ao solo estão em contínuo processo de solubilização, o que aumenta o risco de lixiviação de metais pesados.

A associação de rochas calcárias ao material de origem dos solos 1, 2 e 3 definiu os altos valores de $\mathrm{pH}$ e de $\mathrm{V} \%$, ausência de $\mathrm{Al}^{3+}$ e elevados teores de $\mathrm{Ca}^{2+}$ (Tabela 4). A abundância de feldspatos-K em rochas ígneas ácidas (gnaisse) (PHILIPP, 1998) também contribuiu para os altos teores 
do nutriente nesses solos. $\mathrm{O}$ solo 3, com maior contaminação (maiores teores de $\mathrm{Pb}-\mathrm{HNO}_{3}$ ), apresentou melhores condições químicas; os maiores valores de $\mathrm{pH}$ e de teores de $\mathrm{K}$ e $\mathrm{P}$ (Tabela 4 e posicionamento diferenciado dessas variáveis nas figuras $4 \mathrm{~b}$ e $5 \mathrm{~b}$ ) foram decisivos para o posicionamento das amostras desse solo no lado oposto ao grupo formado pelas amostras dos solos 1 e 2 na ACP (Figuras 4a e 5a).

Não houve variação consistente nos atributos químicos entre as amostras tomadas em diferentes quadrantes para o mesmo solo. Como conseqüência, em ambas as profundidades, o local foi mais importante para separar grupos homogêneos de amostras (Figuras 4a e 5a). As amostras dos solos 1 (referência) e 2 foram colocadas em um mesmo grupo, o que reflete a homogeneidade química e física de suas amostras.

A menor fertilidade, baixos teores de argila e menores valores de capacidade de campo das amostras dos solos 5 e 6 definiram o posicionamento das amostras no lado direito, oposto aos solos 1, 2 e 3 no gráfico da ACP (Figuras 4a e 5a). Os maiores valores de $\mathrm{pH}$ e $\mathrm{V} \%$ e de teores de $\mathrm{K}$ e $\mathrm{P}$ nas amostras do solo 5 em relação ao solo 6 (Tabela 4) foram decisivas para a formação de dois grupos distintos; esses parâmetros foram posicionados em região similar em relação às amostras do solo 5. Mesmo que os valores de $\mathrm{pH}$ acima da neutralidade, observados nas amostras do solo 5, reduz a mobilidade de metais pesados no solo e a contaminação ambiental (HARTER, 1983; KING, 1988; COOK; HENDERSHOT, 1996; AZIZIAN; NELSON, 1998), essa condição pode ser desfavorável ao crescimento de plantas por tornar alguns micronutrientes (principalmente Fe e Mn) menos disponíveis (WALLACE, 1989; PAULETTI et al., 200).

Figura 4. Análise de Componente Principal das análises físicas e químicas da camada de 0 a $5 \mathrm{~cm}$ : valores de "scores" para as amostras analisadas e formação de grupos de amostras semelhantes (a) e valores de "loadings" para as variáveis levando-se em consideração as componentes principais 1 e 2 (b).

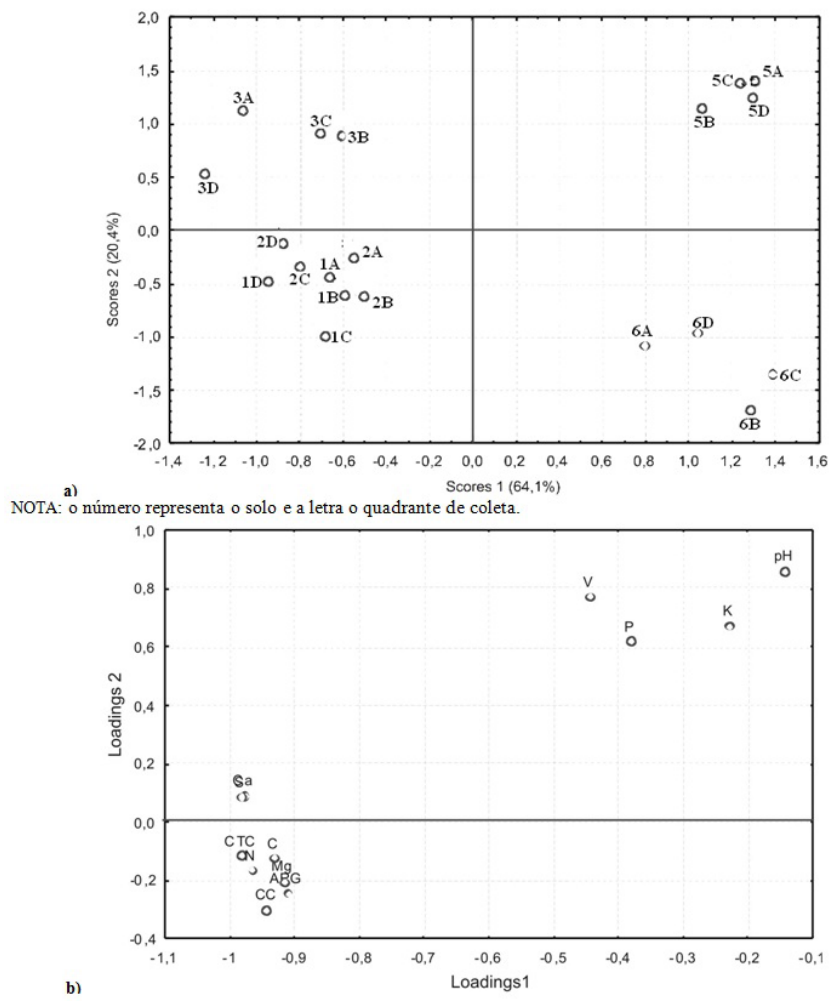




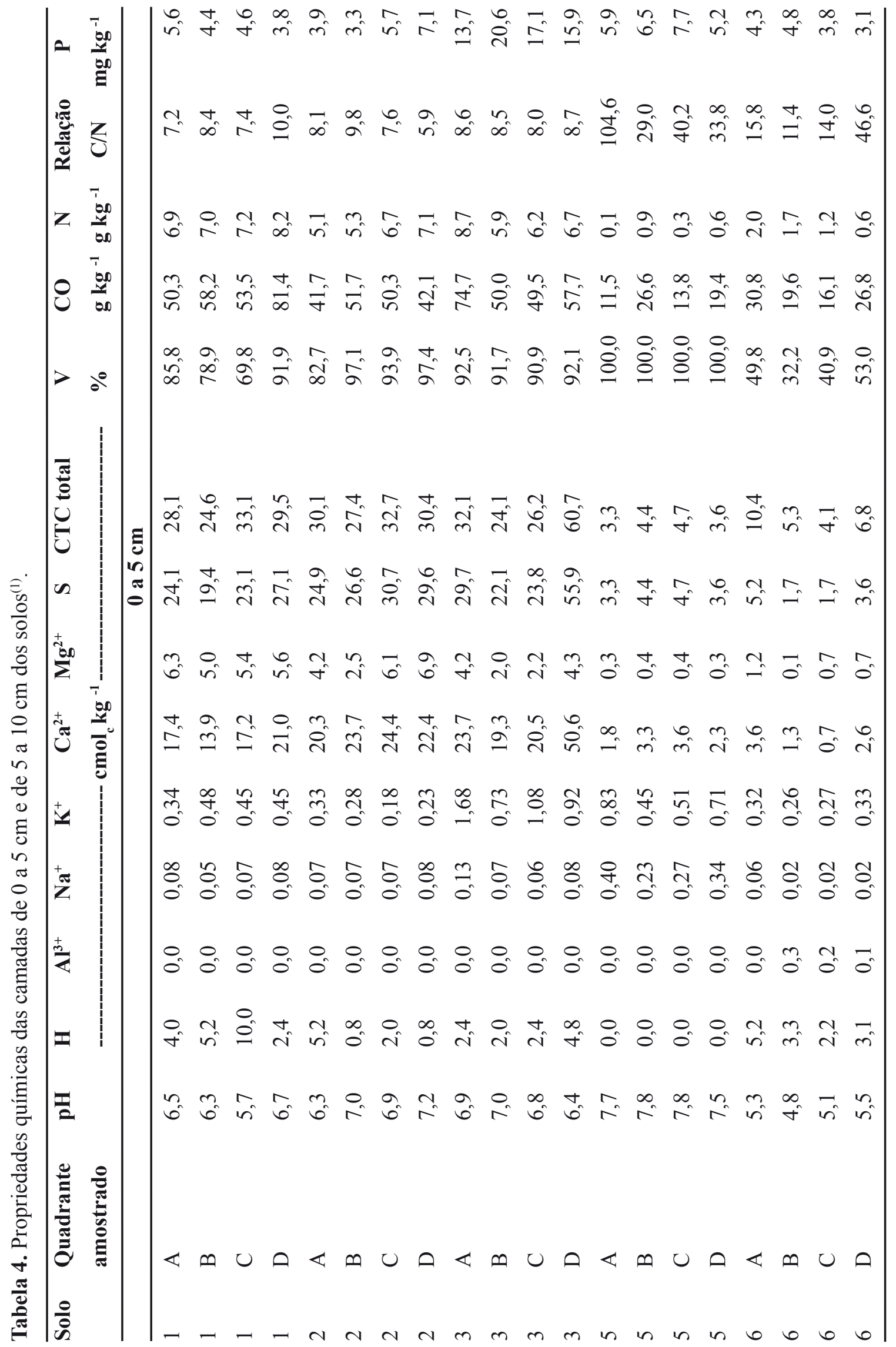


Continuação Tabela 4

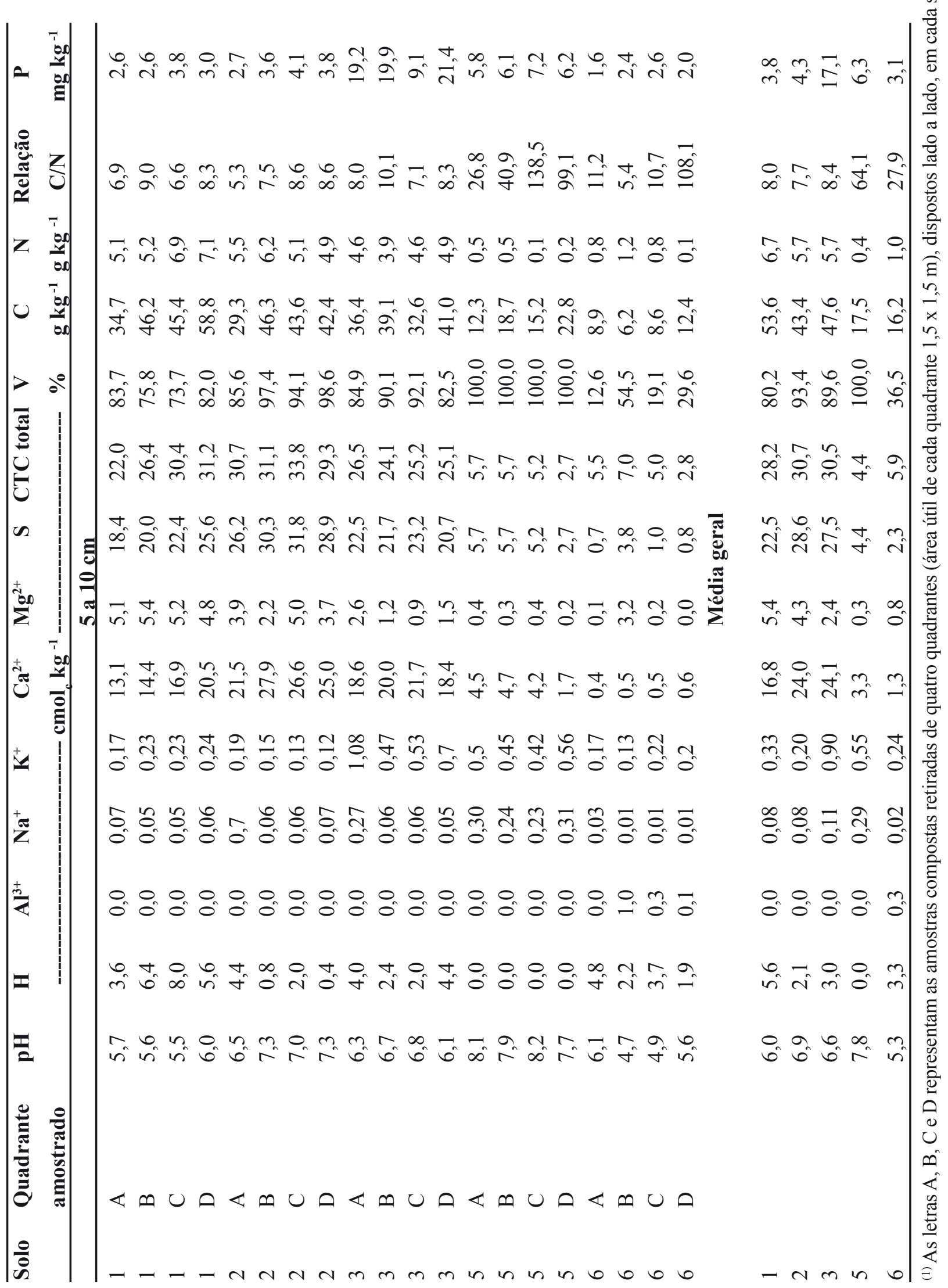


Figura 5. Análise de Componente Principal das análises físicas e químicas da camada de 5 a 10 cm: valores de "scores" para as amostras analisadas e formação de grupos de amostras semelhantes (a) e valores de "loadings" para as variáveis levando-se em consideração as componentes principais 1 e 2 (b).
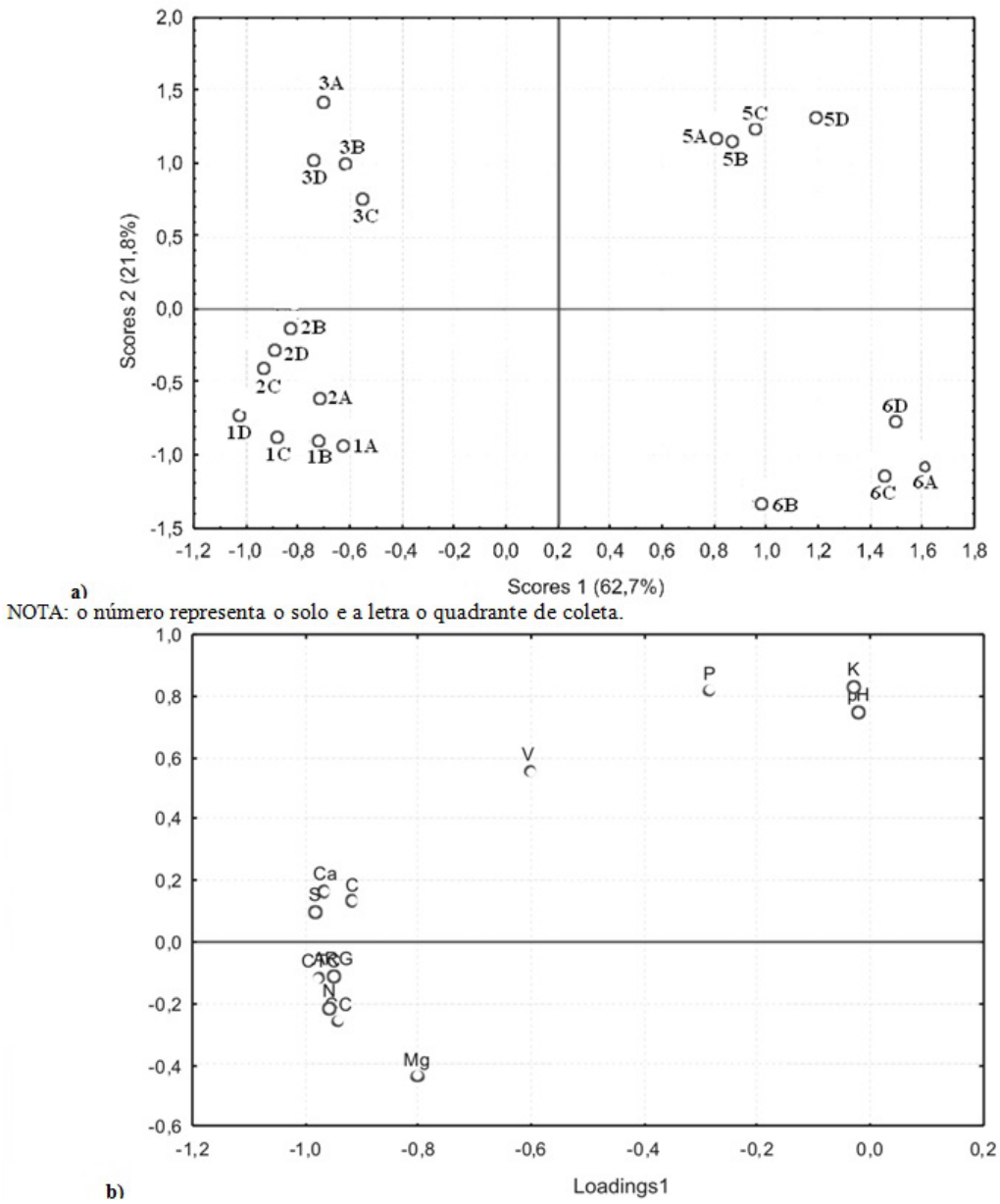

\section{Conclusões}

As atividades de mineração e metalurgia promoveram intensa contaminação dos solos, principalmente, por $\mathrm{Pb}$ e $\mathrm{Zn}$. Os teores de $\mathrm{Pb}$ totais e extraídos com $\mathrm{HNO}_{3}$ 0,5 mol L-1 atingiram 25.930 e $15.370 \mathrm{mg} \mathrm{kg}^{-1}$, respectivamente, o que indica a necessidade de implantação imediata de práticas de remediação na área. A incorporação dos rejeitos ao perfil do solo favoreceu a solubilização do $\mathrm{Pb}$.

Foram identificados dois solos com maior risco de contaminação das águas: solo 5 - águas superficiais por erosão, com maiores teores totais de $\mathrm{Pb}$, associados a cota elevada e declividade acentuada do terreno; solo 3 - águas subterrâneas por lixiviação, principalmente, se houver acidificação do solo, com maiores teores de $\mathrm{Pb}$ extraídos com $\mathrm{HNO}_{3}$ e maior proximidade ao rio Ribeira.

As amostras dos solos 5 e 6 foram agrupadas na análise por componentes principais em função da menor fertilidade e do baixo teor de argila. Já as amostras do solo 3 se diferenciaram das demais por seus maiores teores de nutrientes. Melhores condições físicas e químicas dos solos favorecem o crescimento de plantas, reduzindo a erosão e facilitando trabalhos de fitorremediação da área.

\section{Referências}

AMARAL SOBRINHO, N. M. B.; VELLOSO, A. C. X.; 
COSTA, L. M.; OLIVEIRA, C. Mobilidade de metais pesados em solo tratado com resíduo siderúrgico. Revista Brasileira Ciência do Solo, Viçosa, v. 22, n. 2, p. 345353, 1998.

ANDRADE, M. G.; MELO, V. F.; GABARDO, J.; SOUZA, L. C. P.; REISSMANN, C. B. Metais pesados em solos de área de mineração e metalurgia de chumbo: I - fitoextração. Revista Brasileira Ciência do Solo, Viçosa, v. 33, n. 6, p. 1879-1888, 2009 a.

ANDRADE, M. G.; MELO, V. F.; SOUZA, L. C. P.; GABARDO, J.; REISSMANN, C. B. Metais pesados em solos de área de mineração e metalurgia de chumbo: I formas e disponibilidade. Revista Brasileira Ciência do Solo, Viçosa, v. 33, n. 6, p. 1889-1897, 2009 b.

ANDRÉ, E. M.; CRUZ, M. C. P.; FERREIRA, M. E.; PALMA, L. A. S. Frações de zinco em solo arenoso e suas relações com disponibilidade para Cynodon spp. Revista Brasileira Ciência do Solo, Viçosa, v. 27, n. 3, p. 451-460, 2003.

AZIZIAN, M. F.; NELSON, P. O. Lead sorption, chemically enhanced desorption, and equilibrium modeling in an iron-oxide-coated sand and synthetic groundwater system. In: JENNE, E. A. (Ed.). Adsorption of metals by geomedia: variables, mechanisms, and model ndplications. San Diego: Academic Press, 1998. p. $165-180$.

BARBAR, L. C.; MELO, V. F. Variabilidade das características químicas e mineralógicas de solos da região metropolitana de Curitiba (PR). Scientia Agraria, Curitiba, v. 9, n. 2, p. 187-197, 2008.

BARROS, Y. B. Indicadores biológicos de qualidade de solos de área de mineração e processamento de chumbo, no município de Adrianópolis (PR). 2008. Dissertação (Mestrado Ciência do Solo) - Universidade Federal do Paraná, Curitiba.

BOSSO, S. T.; ENZWEILER, J.; ANGÉLICA, R. Lead bioacessibility in soil and mine wastes after immobilization with phosphates. Water Air Soil Pollution, Netherland, v. 195, n. 1, p. 257-273, 2008.

BURGESS, W. A. Recognition of health in hazards in industry: a review of materials and processes. 2. ed. New York: John Wiley \& Sons, 1995. 537 p.

CAMPOS, M. L.; PIERANGELI, M. A. P.; GUILHERME, L. R. G.; MARQUES, J. J.; CURI, N. Baseline concentration of heavy metals in Brazilian Latosols. Communication Soil Science Plant Analysis, London, v. 34, n. 3/4, p. 547-558, 2003.

CASSIANO, A. M. Fontes de contaminação por metais pesados na bacia do rio Ribeira (SP-PR): estratégias para remediação de uma área de disposição de rejeitos de mineração de Pb-Ag. 2001. São Carlos: UNESP, 2001. Tese (Doutorado Química) - Universidade Estadual de São Paulo, São Carlos.

COOK, N.; HENDERSHOT, W. H. The problem of establishing ecologically based soil quality criteria: The case of lead. Canadian Journal Soil Science, Quebec, v. 76, p. 335-342, 1996.

CUNHA, F. G. Contaminação humana e ambiental por chumbo no vale do Ribeira, nos estados de São Paulo e Paraná, Brasil. 2003. Tese (Doutorado Químca) Universidade de Campinas, Campinas.

ELLIOTT, H. A.; LIBERATI, M. R.; HUANG, C. P. Competitive adsorption of heavy metals by soils. Journal Environmental Quality, Madison, v. 15, n. 3, p. 214-217, 1986.

ELLIS, B.; KNEZEK, B. D. Adsorptions reactions of micronutrients in soils. In: DINAUER, R. C. (Ed.). Micronutrients in agriculture. Madison: ASA/SSSA, 1977. $566 \mathrm{p}$.

EMPRESA BRASILEIRA DE PESQUISA AGROPECUÁRIA - EMBRAPA. Manual de métodos de análise de solo. 2. ed. Rio de Janeiro: EMBRAPA/ CNPS, 1997. 209 p.

EYSINK, G. G. J. Metais pesados no Vale do Ribeira e em Iguape-Cananéia. Revista CETESB de Tecnologia, Curitiba, v. 2, n. 1, p. 6-13, 1988.

FADIGAS, F. S.; AMARAL SOBRINHO, N. M. B.; MAZUR, N.; ANJOS, L. H. C.; FREIXO, A. A. Concentrações naturais de metais pesados em algumas classes de solos Brasileiros. Bragantia, Campinas, v. 61, n. 2, p. 151-159, 2002.

FARRAH, H. N.; PICKERING, W. F. Extraction of heavy metals ions sorbed on clays. Water Air Pollution, Netherland, v. 9, n. 4, p. 491-498, 1978.

GELADI, P.; ISAKSSON, H. L.; LINDQVIST WOLD, S.; ESBENSEN, K. Principal component analysis of multivariate images. Chemometrics Intelligent Laboratory Systems, Oxford, v. 5, n. 3, p. 209-220, 1989.

GOMES, P. C.; FONTES, M. P. F.; COSTA L. M.; MENDONÇA, E. S. Extração fracionada de metais pesados em Latossolo Vermelho Amarelo. Revista Brasileira Ciência do Solo, Viçosa, v. 21, n. 4, p. 543551, 1997.

GUILHERME, L. R. G.; MARQUES, J. J. G. S. M.; PIERANGELI, M. A. P.; ZULIANI, D. Q.; CAMPOS, M. L. Elementos-traço em solos, sedimentos e águas. In: SIMPÓSIO NACIONAL SOBRE RECUPERAÇÃO DE ÁREAS DEGRADADAS, 5., 2002, Belo Horizonte. Anais... Belo Horizonte: Sociedade Brasileira de Áreas 
Degradadas. 2002. p. 30-55.

HARTER, R. D. Effect of soil pH on adsorption of lead, copper, zinc, and nickel. Soil Science Society American Journal, Madison, v. 47, n. 1, p. 47-51, 1983.

HARTER, R. D.; NAIDU, R. Role of metal-organic complexation in metal sorption by soils. Advances Agronomy, New York, v. 55, p. 219-263, 1995.

JACKSON, M. L. Análisis química de suelos. 2. ed. Barcelona: Ediciones Omega, 1970. p. 254-267.

KABATA-PENDIAS, A.; PENDIAS, H. Trace elements in soils and plants. 3. ed. Boca Raton: CRC Press, 2001. $413 \mathrm{p}$.

KING, L. D. Retention of metals by several soils of the Southeastern United States. Journal Environmental Quality, Madison, v. 17, n. 2, p. 239-246, 1988.

KNUDSEN, D.; PETERSON, G. A.; PRATT, P. F. Lithium, sodium, and potassium. In: PAGE, A. L. (Ed.). Methods of soil analysis. Chemical and microbiological properties. Madison: American Society of Agronomy, 1986. p. 225-246.

LIAO, M.; CHEN, C. L.; HUANG, C. Y. Effect of heavy metals on soil microbial activity and diversity in a reclaimed mining wasteland of red soil area. Chinese Journal Environmental Science, Huanjing Kexue, v. 17, n. 5, p. 832-837. 2005.

LIM, C. H.; JACKSON, M. L. Dissolution for total elemental analysis. In: PAGE, A. L. (Ed.). Methods of soil analysis. Chemical and microbiological properties. Madison: American Society of Agronomy, 1986. p. 1-12.

LOGAN, T. J.; CHANEY, R. L. Utilization of municipal wastewater and sludge on land - metals. In: PAGE, A. L.; GEASON, T. L.; SMITH, J. E. JR.; ISKANDAR, I. K.; SOMMERS, L. E. (Ed.). Utilization of municipal wastewater and sludge on land. Riverside: University of California, 1983. p. 235-326.

MORAES, R. P. Transporte de chumbo e metais associados no rio Ribeira de Iguape. 1997. Dissertação (Mestrado Química) - Universidade de Campinas, Campinas.

MUNN, K. J.; EVANS, J.; CHALK, P. M. Mineralization of soil and legume nitrogen in soils treated with metal-contaminated sewage sludge. Soil Biolology Biochemistry, Oxford, v. 32, n. 14, p. 2031-2043, 2000.

OLIVEIRA, M. A. F.; MANIESI, V.; TEIXEIRA, W.; DAITX, E. C. Caracterização isotópica de metabasitos e anfibolitos dos grupos açungui e setuva na porção sul da faixa ribeira. Geologia USP Série Científica, São Paulo, v. 2, n. 1, p. 161-170, 2002.
OLSEN, S. R.; SOMMERS, L. E.; Phosphorus. In: PAGE, A. L.; MILLER, R. H.; KEENEY, D. R. (Ed.). Chemical and microbiological properties. 2. ed. Madison: American Society of Agronomy, 1982. p. 421-422.

PAULETTI, V.; PREVEDELLO, B. M. S.; PISSAIA; A.; SCOPEL, A. Evaluation of nutrient status and grain yield of two corn cultivars under soil aluminum levels after liming. Brazilian Archives Biology Technology, Curitiba, v. 43, n. 3, p. 275-279, 2000.

PHILIPP, R. P. A evolução geológica e tectônica do batólito Pelotas no Rio Grande do Sul. 1998. Tese (Doutorado Geologia) - Universidade de Campinas, Campinas.

RAINBOW, P. S. Trace metal concentrations in aquatic invertebrates: why and so what? Environmental Pollution, v. 120, n. 3, p. 497-507, 2002.

SANGINGA, N.; MUlONGOY, K.; SWIFT, M. J. Contribution of soil organisms to the sustainability and productivity cropping systems in the tropics. Agriculture, Ecosystems \& Environment, Amsterdam, v. 41, n. 2, p. 135-152, 1992.

SEASTED, T. R. The role of microarthropods in decomposition and mineralization processes. Annual Review Entomology, Palo Alto, v. 29, n. 1, p. 25-46, 1984.

SILVA, R. H. P. Geoquímica e impacto ambiental do arsênio no Vale do Ribeira (SP-PR). 1997. Dissertação (Mestrado em Geociências) - Universidade de Campinas, Campinas.

SOON, Y. K.; BATES, T. E. Chemical pools of Cd, Ni, and $\mathrm{Zn}$ in polluted soils and some preliminary indications of their availability to plants. Journal Soil Science, Madison, v. 33, n. 3, p. 477-488, 1982.

SPARKS, D. L. Environmental soil chemistry. London: Academic Press, 2003. 352 p.

UNIVERSIDADE FEDERAL DO PARANÁ - UFPR. Manual de diagnóstico de fertilidade e manejo de solos agrícolas. 2. ed. Curitiba: Imprensa Universitária da UFPR, 2003. 143 p.

WALLACE, A. Effect on liming on trace-element interactions in plant. Soil Science, Madison, v. 147, n. 4, p. 416-421, 1989. 
